\title{
Effect of dietary fiber and threonine content on intestinal barrier function in pigs challenged with either systemic $E$. coli lipopolysaccharide or enteric Salmonella Typhimurium
}

Michael O. Wellington ${ }^{1,2}$, Kimberley Hamonic ${ }^{2}$, Jack E. C. Krone ${ }^{1,2}$, John K. Htoo ${ }^{3}$, Andrew G. Van Kessel ${ }^{2}$ and Daniel A. Columbus ${ }^{1,2^{*}}$

\begin{abstract}
Background: The independent and interactive effects of dietary fiber (DF) and threonine (Thr) were investigated in growing pigs challenged with either systemic E. coli lipopolysaccharide (LPS) or enteric Salmonella Typhimurium (ST) to characterise their effect on intestinal barrier function.

Results: In experiment 1, intestinal barrier function was assessed via oral lactulose and mannitol (L:M) gavage and fecal mucin analysis in pigs challenged with E. coli LPS and fed low fiber (LF) or high fiber (HF) diets with graded dietary Thr. Urinary lactulose recovery and L:M ratio increased $(P<0.05)$ during the LPS inoculation period in LF fed pigs but not in HF fed pigs. Fecal mucin output was increased $(P<0.05)$ in pigs fed HF compared to LF fed pigs. In experiment 2, RT-qPCR, ileal morphology, digesta volatile fatty acid (VFA) content, and fecal mucin output were measured in Salmonella Typhimurium challenged pigs, fed LF or HF diets with standard or supplemented dietary Thr. Salmonella inoculation increased $(P<0.05)$ fecal mucin output compared to the unchallenged period. Supplemental Thr increased fecal mucin output in the HF-fed pigs (Fib $\times T h r ; P<0.05)$. Feeding HF increased $(P<$ $0.05)$ VFA concentration in cecum and colon. No effect of either Thr or fiber on expression of gene markers was observed except a tendency $(P=0.06)$ for increased MUC2 expression with the HF diet. Feeding HF increased goblet cell numbers $(P<0.05)$.

Conclusion: Dietary fiber appears to improve barrier function through increased mucin production capacity (i.e., goblet cell numbers, MUC2 gene expression) and secretion (i.e., fecal mucin output). The lack of effect of dietary Thr in Salmonella-challenged pigs provides further evidence that mucin secretion in the gut is conserved and, therefore, Thr may be limiting for growth under conditions of increased mucin production.
\end{abstract}

Keywords: Barrier function, E. coli lipopolysaccharide, Fiber, Goblet cells, Mucin, Salmonella, Swine, Threonine

\footnotetext{
* Correspondence: dan.columbus@usask.ca

${ }^{1}$ Prairie Swine Centre, Inc., Saskatoon, SK S7H 5N9, Canada

${ }^{2}$ Department of Animal and Poultry Science, University of Saskatchewan,

Saskatoon, SK S7N 5A8, Canada

Full list of author information is available at the end of the article
}

C C The Author(s). 2020 Open Access This article is licensed under a Creative Commons Attribution 4.0 International License, which permits use, sharing, adaptation, distribution and reproduction in any medium or format, as long as you give appropriate credit to the original author(s) and the source, provide a link to the Creative Commons licence, and indicate if changes were made. The images or other third party material in this article are included in the article's Creative Commons licence, unless indicated otherwise in a credit line to the material. If material is not included in the article's Creative Commons licence and your intended use is not permitted by statutory regulation or exceeds the permitted use, you will need to obtain permission directly from the copyright holder. To view a copy of this licence, visit http://creativecommons.org/licenses/by/4.0/. The Creative Commons Public Domain Dedication waiver (http://creativecommons.org/publicdomain/zero/1.0/) applies to the data made available in this article, unless otherwise stated in a credit line to the data. 


\section{Background}

A single layer of epithelial cells separates the intestinal lumen from the underlying tissues of the body and plays a key role in responding to changes in the luminal environment $[1,2]$. The epithelial layer also functions as a barrier allowing for selective nutrient absorption while preventing toxins, bacteria, and other foreign compounds from entering body circulation. Physical and chemical factors present in the intestinal lumen contribute to the functions of the intestinal barrier [3, 4]. In commercial swine production systems, pigs are exposed to environmental and dietary factors that negatively impact barrier function, affecting their production performance and efficiency [5-7]. Indeed, a compromised intestinal barrier is thought to predispose animals to enteric pathogens and luminal toxins, ultimately inducing inflammation, lowering feed intake and efficiency of feed utilization for growth [8,9]. Mucus is a glycoprotein secreted by goblet cells that acts to protect the intestinal epithelium from mechanical, chemical and bacterial injuries [10]. Mucus is a major contributor to improved intestinal barrier function, facilitating an unstirred water layer and an environment that limits direct contact of luminal antigens with the epithelium. Dietary fiber (DF) is thought to have both direct and indirect effects on intestinal health and barrier function, including alterations in mucus secretion and cell proliferation as well as changes in the luminal environment as a result of fermentation metabolites [6,11-13]. However, there are associated negative effects of feeding high DF on endogenous AA losses. Losses of threonine (Thr) are particularly high because mucus contains high amounts of mucin, a Thr rich glycoprotein $[14,15]$. Since mucin is largely resistant to digestion, increased secretion of mucus will result in high endogenous losses of Thr [11, 16]. Although mucin secretion is conserved and prioritized [17], there is evidence that mucin secretion might be sensitive to dietary Thr concentration [18]. Previous studies have reported improved intestinal barrier function, increased goblet cell density and increased expression of MUC2 mRNA in pigs and chickens [19-21] when Thr supply was above dietary requirements for growth. Therefore, the objective of this study was to characterize the independent and interactive effects of DF and Thr on markers related to intestinal health and barrier function in pigs during periods of immune stress induced by enteric pathogen challenge (Salmonella Typhimurium) or a non-pathogenic systemic model ( $E$. coli lipopolysaccharide). It was hypothesized that immune stimulation will negatively affect intestinal barrier function. It was further hypothesized that high DF will improve barrier function due to increased mucus secretion in the gut, regardless of the immune status of growing pigs.

\section{Materials and methods \\ Experimental procedures Experiment 1}

As previously reported by Wellington et al. [22], a total of 90 growing barrows (Camborough Plus $\times$ C3378: PIC Canada Ltd.) with initial body weight of $20.5 \pm 0.75 \mathrm{~kg}$ were individually housed in metabolism crates $(1.4 \mathrm{~m} \times$ $1.5 \mathrm{~m})$ in a temperature-controlled room at $20 \pm 2{ }^{\circ} \mathrm{C}$ at the Prairie Swine Centre, Inc. (Saskatoon, SK, Canada). Briefly, pigs were randomly assigned to 1 of 10 dietary treatments over 9 blocks with a total of 10 pigs per block and 9 pigs per treatment. The dietary treatments were arranged as a $2 \times 2 \times 5$ factorial in a randomized complete block and consisted of a low fiber [LF, 13\% total dietary fiber (TDF)] or high fiber (HF, 20\% TDF) diet and 1 of 5 levels of dietary Thr $[0.49 \%, 0.57 \%$, $0.65 \%, 0.73 \%$, and $0.81 \%$ standardized ileal digestible (SID)]. The HF diets were formulated by partly replacing corn in the LF diet with 5\% wheat bran and 10\% sugar beet pulp. Dietary ingredients and inclusion levels represented typical commercial formulations. The experiment lasted for $16 \mathrm{~d}$ with an 8-d adaptation period followed by two $4 \mathrm{~d}$ collection periods, a pre-ISS period and an ISS period. Immune system stimulation was achieved by intramuscular injection with $E$. coli lipopolysaccharide (LPS; O55:B5, Sigma Aldrich, Oakville, ON, Canada) at an initial dose of $30 \mu \mathrm{g} / \mathrm{kg} \mathrm{BW}$ and repeated after $48 \mathrm{~h}$ at a 15\% increase in dosage [23]. On d 4 of each period, after an overnight fast, pigs were orally dosed using temporary gastric tube (18FR, MED-RX, Canadian Hospital Specialties, Ltd., Oakville, ON, Canada) with a lactulose solution $(0.67 \mathrm{~g} / \mathrm{mL}$ Apo-Lactulose, Apotex Inc. Toronto, ON, Canada) and mannitol solution $(0.43 \mathrm{~g} / \mathrm{mL}$ mannitol, Sigma Aldrich, Oakville, ON, Canada) to provide $0.5 \mathrm{~g}$ and $0.3 \mathrm{~g} / \mathrm{kg} \mathrm{BW}$ lactulose and mannitol, respectively. Following the oral gavage, urine was collected over a 24-h period from each pig. The total urine collected was weighed and a $10 \%$ aliquot was sampled and stored at $-20^{\circ} \mathrm{C}$ for later analysis. Fresh fecal samples were obtained from individual pigs each day during both pre- and post-ISS periods and stored at $-20^{\circ} \mathrm{C}$. At the end of the collection period, fecal samples were pooled and thoroughly mixed for each pig prior to being freeze dried and ground for fecal mucin analysis.

\section{Experiment 2}

As previously reported by Wellington et al. [24], a total of 128 pigs (Camborough Plus $\times$ C3378; PIC Canada Ltd.) of $22.6 \pm 1.6 \mathrm{~kg}$ initial BW were housed in groups of 4 pigs/pen on solid floors lined with rubber mats in a temperature-controlled room $\left(22 \pm 1^{\circ} \mathrm{C}\right)$. Briefly, pens were randomly assigned to 1 of 4 dietary treatments based on the previous study [22] and consisted of an LF 
(13\% TDF) or HF (20\% TDF) diet with either a standard (STD; $0.65 \%$ SID) or supplemental (SUP; 0.78\% SID) Thr level. The HF diets were formulated by partly replacing corn in the LF diet with 5\% wheat bran and 10\% sugar beet pulp. The experiment lasted for a total of 28 $\mathrm{d}$ and consisted of a 7-d adaptation period (unchallenged) and $21 \mathrm{~d}$ post-Salmonella Typhimurium (ST) inoculation period. On $\mathrm{d} 0$ of the challenge period, pigs were orally inoculated twice within $4 \mathrm{~h}$ with a saline solution containing $2.3 \times 10^{9} \mathrm{CFU} / \mathrm{mL}$ of ST selected to be resistant to the antibiotics Novobiocin (Nov+) and Nalidixic acid ( $\mathrm{Nal+}$ ). Fecal samples were collected from 2 pigs in each pen $2 \mathrm{~d}$ before and on $\mathrm{d} 4$ post-ST challenge and stored at $-80^{\circ} \mathrm{C}$ and subsequently freezedried, ground and mixed thoroughly before subsampling for fecal mucin analysis. On d 7 post-inoculation, one $\mathrm{pig} /$ pen representing the average pen BW was humanely euthanized by penetrating captive bolt followed by exsanguination. Subsequently, intestinal tissue (ileum, cecum, and colon) was sampled, snap-frozen in liquid nitrogen, and stored at $-80^{\circ} \mathrm{C}$ for RNA isolation and RT-qPCR. Additionally, ileal tissue samples were stored in $10 \%$ buffered formalin solution (Thermo-Fisher Scientific Ltd., Toronto, ON, Canada) for tissue morphological analysis. Digesta samples (ileum, cecum, and colon) were collected into $15 \mathrm{~mL}$ tubes and stored at $-80^{\circ} \mathrm{C}$ for volatile fatty acid (VFA) analysis.

\section{Analytical procedures \\ In vivo barrier permeability analysis (Experiment 1)}

Urinary analysis for lactulose and mannitol was completed at the National Research Council (Saskatoon, SK, Canada) using ion chromatography based on the procedure of Hurum and Rohrer [25]. Briefly, the urine samples were diluted (1:100) with deionized water and the mixture inverted several times. An aliquot of $1 \mathrm{~mL}$ of the sample mixture was transferred into $1.5 \mathrm{~mL}$ polypropylene injection vials. Lactulose and mannitol concentration was analyzed on a Dionex ICS-3000 ion chromatography system (Thermo Scientific, Sunnyvale, CA, USA) using Chromeleon software (version 6.80 SR10, build 2818) with a Dionex CarboPac MA1 $4 \times 50 \mathrm{~mm}$ guard followed by a Dionex CarboPac MA1 BioLC Analytical $4 \times 250$ mm column (Thermo Scientific, Sunnyvale, CA, USA). The mobile phase was $480 \mathrm{mmol} / \mathrm{L} \mathrm{NaOH}$ at a flow rate of $0.4 \mathrm{~mL} / \mathrm{min}$. The detector was programmed to quantify using the calibration curves run with the samples to yield the amount of lactulose or mannitol $(\mu \mathrm{g} / \mathrm{mL})$. Standards were prepared and analyzed with each batch of urine samples.

\section{Total fecal mucin analysis (Experiment 1 and 2)}

Fecal mucin concentration was analyzed according to methods described previously by Bovee-Oudenhoven et al. [26] with modifications according to the kit manufacturer (Fecal mucin assay kit, \#CSR-FFA-MU-K01E, CosmoBio, Ltd., Tokyo, Japan) to quantify NAcetylgalactoseamine. Fluorescence emission values at $383 \mathrm{~nm}$ were recorded following excitation at $336 \mathrm{~nm}$ (Synergy $^{\text {ma }}$ Multi-Mode Reader, BioTex Instruments, Inc., Vermont, USA), and plotted on a standard curve of NAcetylgalactoseamine provided in the kit to determine fecal mucin concentration (mg mucin/g of fecal DM). In experiment 1 , daily fecal DM output was estimated based on recorded daily feed intake and apparent fecal dry matter digestibility was determined via inclusion of an indigestible marker in the diet [22]. Total fecal mucin output was then calculated via mucin concentration $(\mathrm{mg}$ mucin/g fecal DM) corrected for daily fecal DM output. As the same diets were used, the same digestibility value was applied to recorded daily feed intake to estimate total mucin output for Experiment 2.

\section{Ileal morphology and goblet cell numbers (Experiment 2)}

Ileal tissue samples were obtained $15 \mathrm{~cm}$ from the ileocecal junction and immediately fixed in $10 \%$ buffered formalin. The fixed intestinal segments were embedded in paraffin and sectioned for intestinal morphology (Prairie Diagnostic Services, Saskatoon, SK). Briefly, sections of the tissue were deparaffinized in xylene, rehydrated and stained with haematoxylin and eosin. Slide images were measured at $10 \times$ magnification using an Axio Star Plus light microscope (Axio Scope A1; Carl Zeiss Gottingen, Germany). The villus height and crypt depth of each tissue were measured using the AxioVision Rel 4.8 software (Carl Zeiss Canada Ltd., Toronto, $\mathrm{ON}$ ) on a minimum of 10 well-oriented villi and their corresponding crypts per sample. Goblet cell counts were determined by preparing tissue samples as indicated above and staining with Alcian Blue and Periodic Acid Schiff as previously described [27]. The slides were then viewed under a light microscope at $10 \times$ magnification (Axio Scope A1; Carl Zeiss Gottingen, Germany). For each tissue sample, 10 well-oriented villi were selected, and goblet cells were counted in a region within $100 \mu \mathrm{m}$ length of the villi.

\section{Volatile fatty acid analysis (Experiment 2)}

Volatile fatty acid analysis followed the procedure by Khorasani et al. [28] and Lenahan et al. [29]. Briefly, digesta samples (ileum, cecum, and colon) were diluted with $25 \%$ metaphosphoric acid at a 2:1 ratio (w/v). Samples were centrifuged at $12,000 \times \mathrm{g}$ for $10 \mathrm{~min}$ and the supernatant was collected into $2 \mathrm{~mL}$ centrifuge tubes and further centrifuged at $16,000 \times g$ for $10 \mathrm{~min}$. Following that, the supernatant was collected and filtered through $0.45 \mu \mathrm{m}$ PVDA filter (Fisher Scientific, Hampton, New Hampshire, USA) into $1.5 \mathrm{~mL}$ tubes. An 
internal standard $(4.56 \mu \mathrm{mol} / \mathrm{mL}$ isocaproic acid in 0.15 $\mathrm{mol} / \mathrm{L}$ oxalic acid) was added at $0.2 \mathrm{~mL}$ to $1 \mathrm{~mL}$ of the filtered sample supernatant and inverted to mix thoroughly. The VFA were determined on an Agilent 6890 gas chromatograph with a flame ionization detector (Agilent Technologies, Santa Clara, California, USA) and a capillary column ZB-FFAP ( $30 \mathrm{~m}$ length $\times 0.32 \mathrm{~mm}$ width $\times 0.25 \mu \mathrm{m}$ film thickness; ZEBRON, Phenomenex, Torrance, California, USA). The initial oven temperature was set at $90^{\circ} \mathrm{C}$ and a hold time of $0.1 \mathrm{~min}$, then followed by the $1^{\text {st }}$ ramp; $10{ }^{\circ} \mathrm{C}$ per minute which increased until $170^{\circ} \mathrm{C}$ with a hold time of $6 \mathrm{~s}$. The $2^{\text {nd }}$ ramp was $20^{\circ} \mathrm{C}$ per minute up to $230{ }^{\circ} \mathrm{C}$ with and a hold time of $2 \mathrm{~min}$. Hydrogen gas was used for the FID and helium gas was used as a carrier.

\section{Gene expression analysis (Experiment 2)}

Tissue samples stored at $-80^{\circ} \mathrm{C}$ were ground in liquid nitrogen with mortar and pestle and total RNA was extracted from tissue samples using TRIzol reagent (Invitrogen, Carlsbad, CA) according to the manufacturer's protocol. The RNA concentration and quality were determined using a spectrophotometer (NanoDrop 2000 spectrophotometer, Thermo Fisher Scientific Inc., Delaware, USA) with optical density ratio (260:280) between 1.8 and 2.0. The integrity of RNA was then assessed by gel electrophoresis. Reverse transcription was carried out using a high capacity cDNA reverse transcription kit (Applied Biosystems, CA, USA) with random hexamer primers. Each $20 \mu \mathrm{L}$ of reaction mix contained $0.8 \mu \mathrm{L}$ of $10 \mu \mathrm{mol} / \mathrm{L}$ primer concentration for each forward and reverse primer, $6.4 \mu \mathrm{L}$ of nuclease-free water, $10 \mu \mathrm{L}$ of EVA Green supermix (Bio-Rad Laboratories, CA, USA) and $2 \mu \mathrm{L}(2 \mathrm{ng} / \mathrm{qPCR}$ reaction) of template cDNA. Standard curves were made for each gene using a 5-fold serial dilution of pooled cDNA samples from all experimental treatments. PCR efficiency between 90\% and $110 \%$ were accepted. All genes (Table 1) were analyzed with a standard dilution series prepared from cDNA on the same plate and the starting quantities (recorded as arbitrary values) calculated for each gene on each plate.
Arbitrary values for genes of interest were normalized using the mean of the arbitrary values for GAPDH and RPL19, which were not affected by treatment.

\section{Statistical analyses}

Data were tested for normality using the Shapiro-Wilk test (PROC UNIVARIATE, SAS 9.4, SAS Institute Inc., Cary, NC). In experiment 1 , all data were analyzed as a $2 \times 2 \times 5$ factorial in a randomized complete block design (PROC MIXED, SAS 9.4, SAS Institute Inc., Cary, NC). The model included main effects of [a] fiber level (High or Low DF), [b] period (ISS or Pre-ISS) [c] threonine level $(0.49 \%, 0.57 \%, 0.65 \%, 0.73 \%$, and $0.81 \%$ SID) and their interactions and block as a random effect. In experiment 2, VFA, qPCR, and ileal morphology and goblet cell samples were analyzed as $2 \times 2$ factorial arrangement in a randomized complete block design. The model included the main effects of [a] fiber (High or Low DF) and [b] threonine (STD Thr or SUP Thr) and their interaction and block as a random effect. Data for the fecal mucin output were analyzed as $2 \times 2 \times 2$ factorial arrangement in a randomized complete block design. The model included the main effects of [a] fiber (High or Low DF) and [b] threonine (STD Thr or SUP Thr) and [c] period (pre-ST inoculation and post-ST inoculation) and their interactions and block as a random effect. Significant differences were determined at $P<$ 0.05 and a trend toward significance considered at $P \leq$ 0.10 . When significance was observed, the means were separated according to the least significance difference (LSD) method (PDIFF option in SAS 9.4, SAS Institute Inc., Cary, NC).

\section{Results}

\section{In vivo barrier permeability (Experiment 1 )}

There was no Thr effect on lactulose or mannitol recovery or lactulose:mannitol (L:M) ratio. As shown in Fig. 1, a significant period $\times$ fiber interaction $(P<0.01)$ was observed on lactulose recovery and L:M ratio (Fig. 1a and c). When no immune stimulation was present, lactulose recovery and L:M ratio was not different between LF

Table 1 Primers used in quantitative PCR analysis ${ }^{a}$

\begin{tabular}{lllll}
\hline Gene & Forward $\left(5^{\prime}\right.$ to $\left.3^{\prime}\right)$ & Reverse $\left(5^{\prime}\right.$ to $\left.3^{\prime}\right)$ & AT, ${ }^{\circ} \mathrm{C}$ & NCBI accession number \\
\hline RPL19 & AACTCCCGTCAGCAGATCC & AGTACCCTTCCGCTTACCG & 60 & AF_435591 \\
MUC2 & ACCCGCACTACGTCACCTTC & GGCAGGACACCTGGTCATTG & 62 & BX671371 \\
CLDN4 & CAACTGCGTGGATGATGAGA & CCAGGGGTTGTAGAAGTCG & 60 & NM_001161637.1 \\
GAPDH & CTTCACGACCATGGAGAAGG & CCAAGCAGTTGGTGGTACAG & 63 & AF017079 \\
ZO-1 & ACGGCGAAGGTAATTCAGTG & CTTCTCGGTTTGGTGTCTG & 60 & XM_003353439.2 \\
Casp3 & TCCTGCTTTCTGCAGCTCTC & GGGTGGAAGGTGTGGAATG & 62 & NM_213867 \\
\hline
\end{tabular}

${ }^{a}$ GAPDH glyceraldehyde 3-phosphate dehydrogenase, RPL19 ribosomal protein-L19, ZO1 Zonula Occludin -1,MUC2 Mucin-2, CLDN-4 Claudin-4, IL8 Interleukin-8, Casp3 Caspase-3, AT annealing temperature 

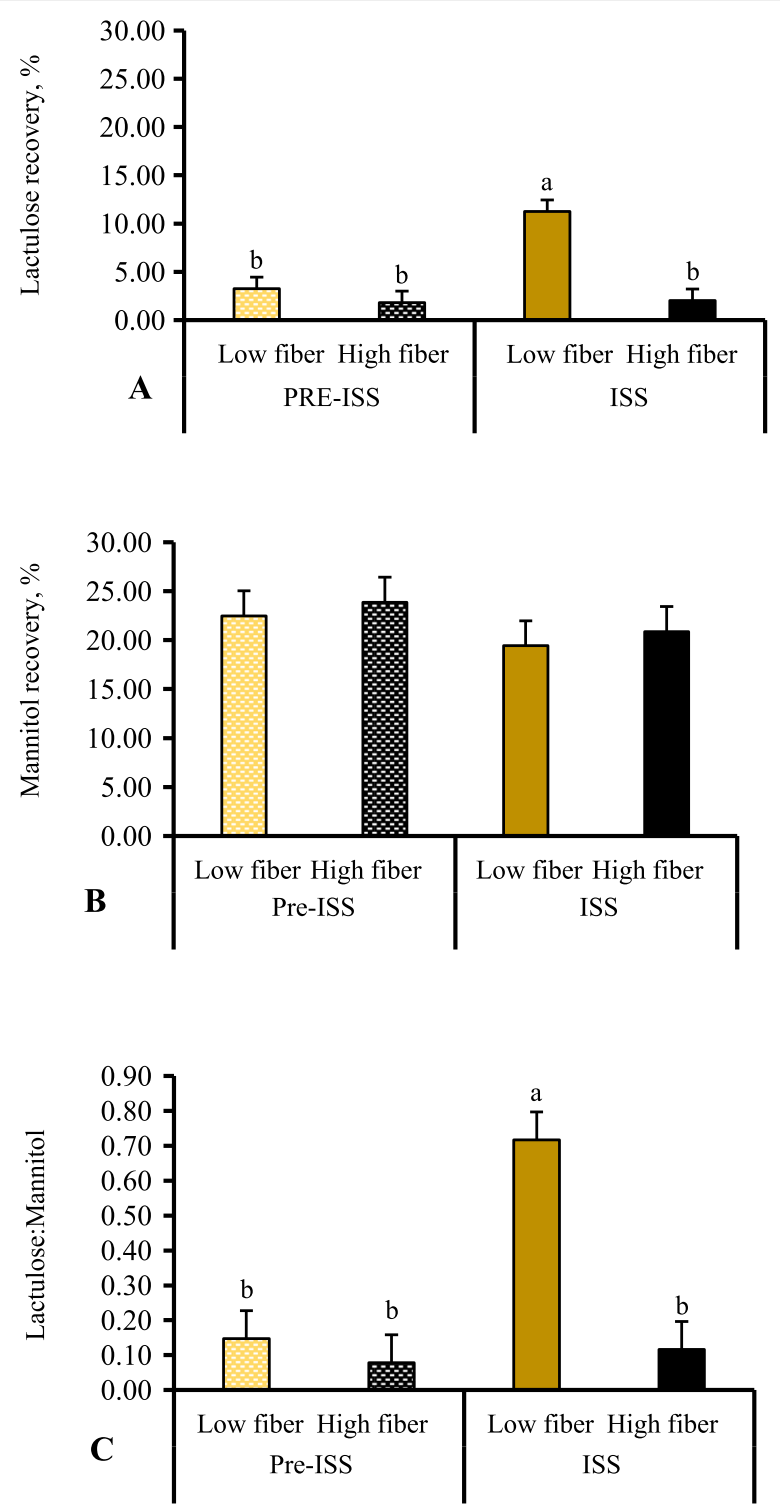

Fig. 1 Urinary lactulose (a), mannitol (b) and lactulose:mannitol ratio (c) in E. coli lipopolysaccharide challenged and unchallenged pigs fed either high or low fiber diets with graded dietary threonine levels. A total of 9 replicate pigs/treatment were used in the analysis

and HF-fed pigs, however following ISS, lactulose recovery and L:M ratio was increased in LF-fed pigs, but not in HF-fed pigs. The recovery of mannitol was not significantly affected $(P>0.05$, Fig. $1 b)$ by either Thr, fiber or period, with no interaction.

\section{Total fecal mucin output (Experiment 1 and 2)}

In experiment 1 , the total fecal mucin output was determined in feces of pigs during pre-ISS and ISS periods and data are presented in Fig. 2. Neither dietary Thr nor ISS by LPS had an effect on total fecal mucin output $(P>0.05)$, however, total fecal mucin output was significantly increased in the HF fed pigs $(P<0.05)$.
In experiment 2 , before ST inoculation a lower $(P<$ 0.01 ) total fecal mucin output was observed compared to total fecal mucin output post ST inoculation (Fig. 3a). A fiber $\times$ Thr interaction (Fig. 3b; $P<0.05$ ) on total fecal mucin output was observed, where Thr supplementation increased total fecal mucin output to a greater extent in pigs fed HF diet compared to LF-fed pigs.

Ileal morphology and goblet cell numbers (Experiment 2) There were no significant effects of fiber, Thr, or an interaction on the villus height, crypt depth, or villus height:crypt depth ratio $(P>0.05)$ in ileal tissue samples of pigs $7 \mathrm{~d}$ post-ST inoculation (Table 2). No effect of Thr $(P>0.05)$ was observed on goblet cell numbers, 
however, goblet cell numbers were increased $(P<0.05)$ in HF-fed pigs compared to the LF-fed pigs (Fig. 4).

\section{Volatile fatty acid concentration (Experiment 2)}

Results for VFA concentration in digesta are presented in Table 3. In the ileal digesta, there were no effects of fiber, Thr or their interaction on the concentration of VFA. In the cecal digesta, HF increased $(P<0.05)$ the concentration of acetate, propionate and the total VFA, but had no significant effect on butyrate concentration $(P>0.05)$. Interestingly, we observed that the total VFA concentration, primarily influenced by the acetate concentration in cecal digesta increased $(P<0.01)$ with SUP Thr. In the colonic digesta, we observed no significant Thr effect $(P>0.05)$ on VFA concentration. However, HF increased $(P<0.01)$ colonic concentration of acetate, with a tendency $(P=0.08)$ to increase butyrate concentration and no effect $(P>0.05)$ on propionate concentration. Total VFA concentration in the colonic digesta was higher $(P<0.05)$ in the HF fed pigs than in LF fed pigs.

\section{Gene expression of markers for barrier function and gut health (Experiment 2)}

Gene expression is presented in Fig. 5 as relative expression [arbitrary units] for ileal and colonic tissue samples. In the ileum, there was a tendency for greater expression of MUC2 $(P=0.06)$, and IL8 $(P=0.10)$ with the HF diet (Fig. 5a). There was no significant effect of Thr or interaction of Thr and fiber on the ileal expression of selected genes. There were no significant treatment effects on the expression of marker genes in the colon $(P>0.05$; Fig. 5b).

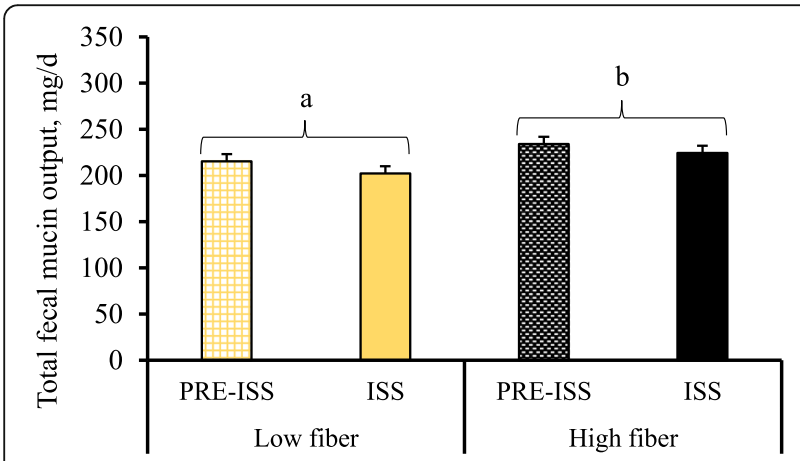

Fig. 2 Total fecal mucin output (mg/d) in LPS challenged and unchallenged pigs fed high or low fiber with graded dietary threonine. Total fecal mucin output was estimated using determined mucin concentration in feces and estimated total fecal output based on previously determined dry matter digestibility. A total of 9 replicate pigs/treatment were used in the analysis. There was a significant effect of fiber $(P<0.05)$ with no effect of Thr or period $(P>0.05)$ on total fecal mucin output
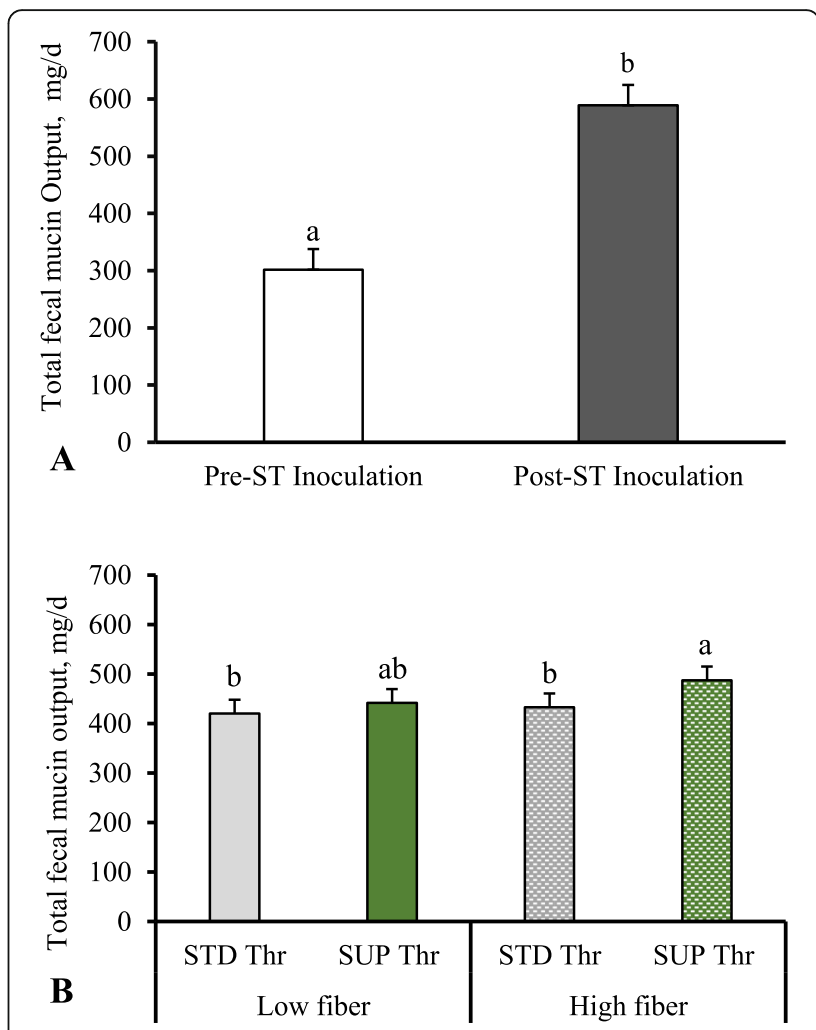

Fig. 3 Total fecal mucin output (mg/d) 2 d before and $4 \mathrm{~d}$ postSalmonella Typhimurium inoculation in pigs fed high or low fiber diets with either standard or supplemental dietary threonine. Total fecal mucin output was estimated using determined mucin concentration in feces and estimated total fecal output based on previously determined dry matter digestibility. A total of 8 replicate pigs/treatment were used in the analysis. Total fecal mucin output was higher post-ST inoculation $(P<0.01)$ compared to output preinoculation (a). There was a significant fiber $\times$ Thr interaction $(P<$ 0.05) on total fecal mucin output (b)

\section{Discussion}

There is a growing research interest in relation to the effects of DF on intestinal health and barrier function. Previous work has demonstrated both direct and indirect roles of DF on intestinal health and barrier function, largely associated with the modulatory effect of DF on microbial environment and the subsequent production of VFA which affects intestinal health and barrier function $[6,30,31]$. Similarly, immune challenge has been shown to affect intestinal health and barrier function as demonstrated by reduced villi height and crypt depth and increased mast cells in LPS challenged weaned pigs [9]. In addition, enteric $E$. coli challenge has been shown to disrupt tight junction assembly and reduce intestinal barrier function in rats [32]. On the other hand, AA are known to play physiological roles as regulators of important functions, apart from participating in protein synthesis [33]. For example, Thr is reported to play an essential role in maintaining mucosal integrity and 
Table 2 Ileal morphology in pigs' 7-d post-Salmonella Typhimurium inoculation ${ }^{\text {a }}$

\begin{tabular}{|c|c|c|c|c|c|c|c|c|}
\hline \multirow[t]{2}{*}{ Item } & \multicolumn{2}{|l|}{ Low fiber } & \multicolumn{2}{|c|}{ High fiber } & \multirow[t]{2}{*}{ SEM $^{d}$} & \multicolumn{3}{|c|}{$P$-value } \\
\hline & $\mathrm{STD}^{\mathrm{b}} \mathrm{Thr}$ & $\overline{S U P^{C}} \mathrm{Thr}$ & STD Thr & SUP Thr & & Fiber & Thr ${ }^{\mathrm{e}}$ & Fiber $\times$ Thr \\
\hline Villus height, $\mu \mathrm{m}$ & 433.9 & 438.8 & 446.4 & 434.2 & 25.6 & 0.867 & 0.859 & 0.697 \\
\hline Crypt depth, $\mu \mathrm{m}$ & 268.7 & 290.9 & 313.5 & 292.7 & 17.6 & 0.157 & 0.963 & 0.188 \\
\hline $\mathrm{VH}: C D^{f}$ & 1.69 & 1.59 & 1.46 & 1.57 & 0.10 & 0.207 & 0.998 & 0.271 \\
\hline
\end{tabular}

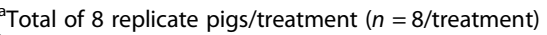

${ }^{\mathrm{b}}$ STD Thr Standard Thr (0.65\% standardized ileal digestible)

'SUP Thr Supplemental Thr (0.78\% standardized ileal digestible)

${ }^{\mathrm{d}}$ SEM Standard error of the mean

${ }^{\mathrm{e}} \mathrm{Thr}$ threonine

${ }^{f} \mathrm{VH}: C D$ villus height:crypt depth

barrier function by supporting mucin secretion [27, 34]. As such, dietary Thr content has been reported to affect mucin dynamics $[18,35,36]$ and support intestinal barrier function and gut health [37]. The aim of the present study was, therefore, to evaluate the independent and combined effects of dietary fiber and Thr on intestinal health and barrier function, using different conditions of immune challenge, including a systemic immune challenge using intravenously administered $E$. coli LPS or enteric challenge with oral Salmonella Typhimurium. In the first experiment, we used the L:M absorption test to measure barrier permeability [38-40], as the design allowed for total urine collection which has been reported to improve the accuracy of this method [39-42]. In experiment 2, tissue analysis for histology and gene expression were used to assess barrier function. In both experiments, fecal samples were analyzed for fecal mucin concentration and further estimation of total fecal mucin output based on previously determined dry matter digestibility and fecal output [22].

In experiment 1 , we evaluated the effect of systemic LPS injection as an immune stimulatory agent on barrier function and further characterized the role of fiber and Thr on the intestinal barrier function with or without LPS induced immune challenge. Previous work has

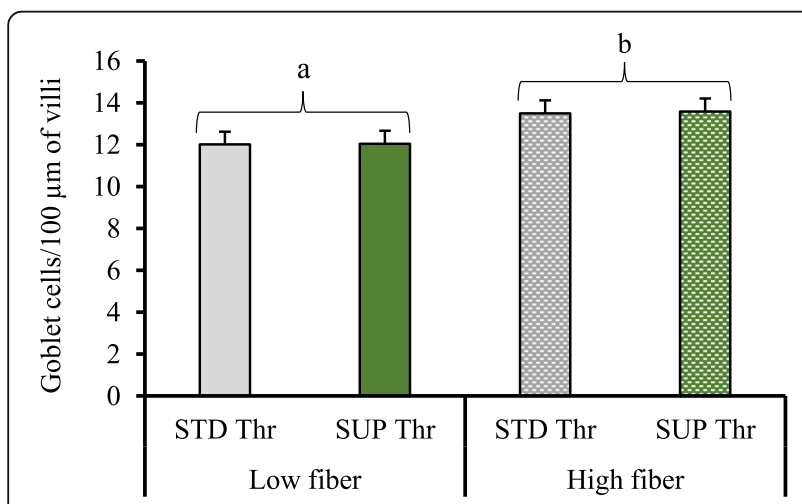

Fig. 4 Goblet cell counts (number/100 $\mu$ m length of villi) of pigs challenged with Salmonella Typhimurium. We observed a significant $(P=0.04)$ increase in goblet cell number with high fiber diets. A total of 8 replicate pigs/treatment were used in the analyses validated the use of lactulose and mannitol as a credible method of determining intestinal barrier permeability in pigs [39-42]. Movement of lactulose across the intestinal epithelium occurs only through paracellular routes whereas movement of mannitol occurs through both paracellular and transcellular pathways [42]. Therefore, high lactulose recovery is an indicator of increased intestinal permeability [39]. Dietary factors (e.g. fiber) could influence the absorption pathways and metabolism of both these sugars. It is assumed that both sugars will be affected equally by pre-absorptive dietary influences, however, mannitol is regarded more as a normalizing control [42] and, therefore, reporting the L:M ratio is more indicative of response to dietary treatments. In the present study, ISS increased the L:M ratio in LF but not HF-fed pigs which is an indication of reduced barrier function during LPS induced ISS. Previously, the effect of LPS on increased intestinal permeability was reported to occur largely as a result of secondary effect mechanisms, such as oxidative stress to the intestinal epithelium $[43,44]$. Observations from the current study suggest that, under conditions of immune stress, intestinal barrier function is disrupted, but feeding a high DF may provide a protective effect on the gut and contribute to improved barrier function. Since increased DF has been reported to increase mucin secretion and potentially contribute to barrier function, total fecal mucin output was measured in the same group of pigs. The absence of an LPS induced effect on total fecal mucin output is contrary to previous studies where systemic LPS was administered [45, 46]. However, the measurement for mucin secretion (i.e., mucosal scrapings) used in those studies was different from the fecal mucin measurement used in the present study. Hence, the lack of effect of LPS on fecal mucin is likely due to the limited direct effects of a systemic LPS induced immune stimulation on intestinal mucin production. However, it should also be noted that fecal mucin analysis may underestimate small intestinal mucin secretion due to the possibility of microbial fermentation of mucus in the hindgut $[47,48]$. Thus, fecal mucin analysis may not have detected a mucin-secretory response to LPS in the 
Table 3 Effect of fiber and threonine on volatile fatty acid concentration in digesta of pigs challenged with Salmonella Typhimurium ${ }^{\text {a }}$

\begin{tabular}{|c|c|c|c|c|c|c|c|c|}
\hline & \multicolumn{2}{|l|}{ Low fiber } & \multicolumn{2}{|c|}{ High fiber } & \multirow[t]{2}{*}{ SEM $^{d}$} & \multicolumn{3}{|c|}{$P$-value } \\
\hline & $\mathrm{STD}^{\mathrm{b}} \mathrm{Thr}$ & $\overline{\text { SUPC Thr }}$ & STD Thr & $\overline{\text { SUP Thr }}$ & & Fiber & $\mathrm{Thr}^{\mathrm{e}}$ & Fiber $\times$ Thr \\
\hline \multicolumn{9}{|l|}{ Cecum, $\mu \mathrm{mol} / \mathrm{g}$} \\
\hline Acetate & 58.31 & 66.29 & 64.41 & 87.33 & 4.71 & $<0.01$ & $<0.01$ & 0.089 \\
\hline Propionate & 45.02 & 48.5 & 55.56 & 63.86 & 5.91 & $<0.05$ & 0.347 & 0.699 \\
\hline Butyrate & 25.56 & 29.47 & 21.47 & 26.16 & 2.76 & 0.248 & 0.183 & 0.902 \\
\hline Total VFA & 128.9 & 144.26 & 141.44 & 177.35 & 9.37 & $<0.05$ & $<0.01$ & 0.264 \\
\hline \multicolumn{9}{|l|}{ Colon, $\mu \mathrm{mol} / \mathrm{g}$} \\
\hline Acetate & 46.39 & 45.99 & 67.69 & 57.06 & 7.37 & $<0.01$ & 0.319 & 0.354 \\
\hline Propionate & 25.65 & 25.35 & 29.01 & 27.4 & 4.18 & 0.473 & 0.798 & 0.860 \\
\hline Butyrate & 13.34 & 15.24 & 18.32 & 18.42 & 2.75 & 0.083 & 0.659 & 0.692 \\
\hline Total VFA & 85.38 & 86.65 & 115.02 & 102.87 & 12.93 & $<0.05$ & 0.613 & 0.533 \\
\hline \multicolumn{9}{|l|}{ Ileum, $\mu \mathrm{mol} / \mathrm{g}$} \\
\hline Acetate & 13.76 & 14.2 & 14.86 & 12.64 & 3.66 & 0.923 & 0.713 & 0.583 \\
\hline Propionate & 0.1 & 0.31 & 0.43 & 0.54 & 0.03 & 0.151 & 0.381 & 0.758 \\
\hline Butyrate & 0.85 & 0.7 & 0.41 & 0.76 & 0.03 & 0.468 & 0.696 & 0.328 \\
\hline Total VFA & 14.68 & 15.21 & 15.69 & 13.95 & 4.08 & 0.961 & 0.819 & 0.669 \\
\hline
\end{tabular}

${ }^{a}$ Total of 8 replicate pigs/treatment $(n=8 /$ treatment)

${ }^{\mathrm{b}}$ STD Thr Standard threonine

'SUP Thr Supplemental threonine

${ }^{\mathrm{d}}$ SEM Standard error of the mean

e Thr Threonine

${ }^{f}$ VFA Volatile fatty acid

case where the LPS mucin response was limited to the small intestine. The HF diet increased the total fecal mucin output in the present study consistent with previous reports $[49,50]$, including reports demonstrating increased ileal mucosal protein losses (e.g. mucin) $[16,51]$ with increased DF. The increased mucin secretion in response to high DF in the present study may directly contribute to protection against paracellular lactulose transport but may also indicate other concurrent changes in barrier function affecting transcellular permeability in response to systemic LPS. The lack of effect of systemic LPS on mucin production provides support for the lack of additivity between high DF and ISS on Thr requirements as previously reported [22].

In experiment 2, the effects of dietary fiber and Thr on intestinal health and barrier function were further evaluated in pigs challenged with an enteric pathogen (i.e., Salmonella Typhimurium).

Measuring the output of mucin in feces provides information on the net output of mucin secreted, largely into the hindgut [52]. The increase in total fecal mucin output with enteric ST inoculation agrees with a previous study that reported increased mucin secretion following immune stress in rats induced by live pathogenic $E$. coli [45]. Although there is some information indirectly relating the impact of immune stimulation on mucus secretion in pigs [53] and chickens [54], the present study demonstrates direct evidence that enteric Salmonella Typhimurium challenge increases mucus secretion. This contrasts the lack of fecal mucin output response in LPS challenged pigs reported here. As outlined in our previous work [24], Salmonella Typhimurium challenge induced an immune response in pigs, as indicated by clinical response data (rectal temperature, acute phase proteins, and Salmonella shedding), without any mitigating effect of high DF. Unlike in experiment 1, we observed an increase in fecal mucin output with Salmonella inoculation as compared with systemic LPS administration suggesting significant direct effects of enteric pathogen on intestinal mucin production, which likely reduced the expected effects of high DF on mucin production. As previously reported [24], supplemental Thr improved growth performance in Salmonella-challenged pigs, regardless of DF content, however, this increase was less with high DF. In addition, in the current study we observed a fiber by Thr interaction on fecal mucin output, in which supplemental Thr increased fecal mucin output in HF but not LF-fed pigs. It has been shown that mucin production is conserved and prioritized over other functions requiring Thr (e.g., protein anabolism) in pigs [17] and may be mobilized from endogenous proteins (e.g., muscle) to meet increased $\mathrm{Thr}$ demands associated with inflammation [55]. The results of the current study provide further evidence that mucin production is prioritized in Salmonella-challenged pigs, 

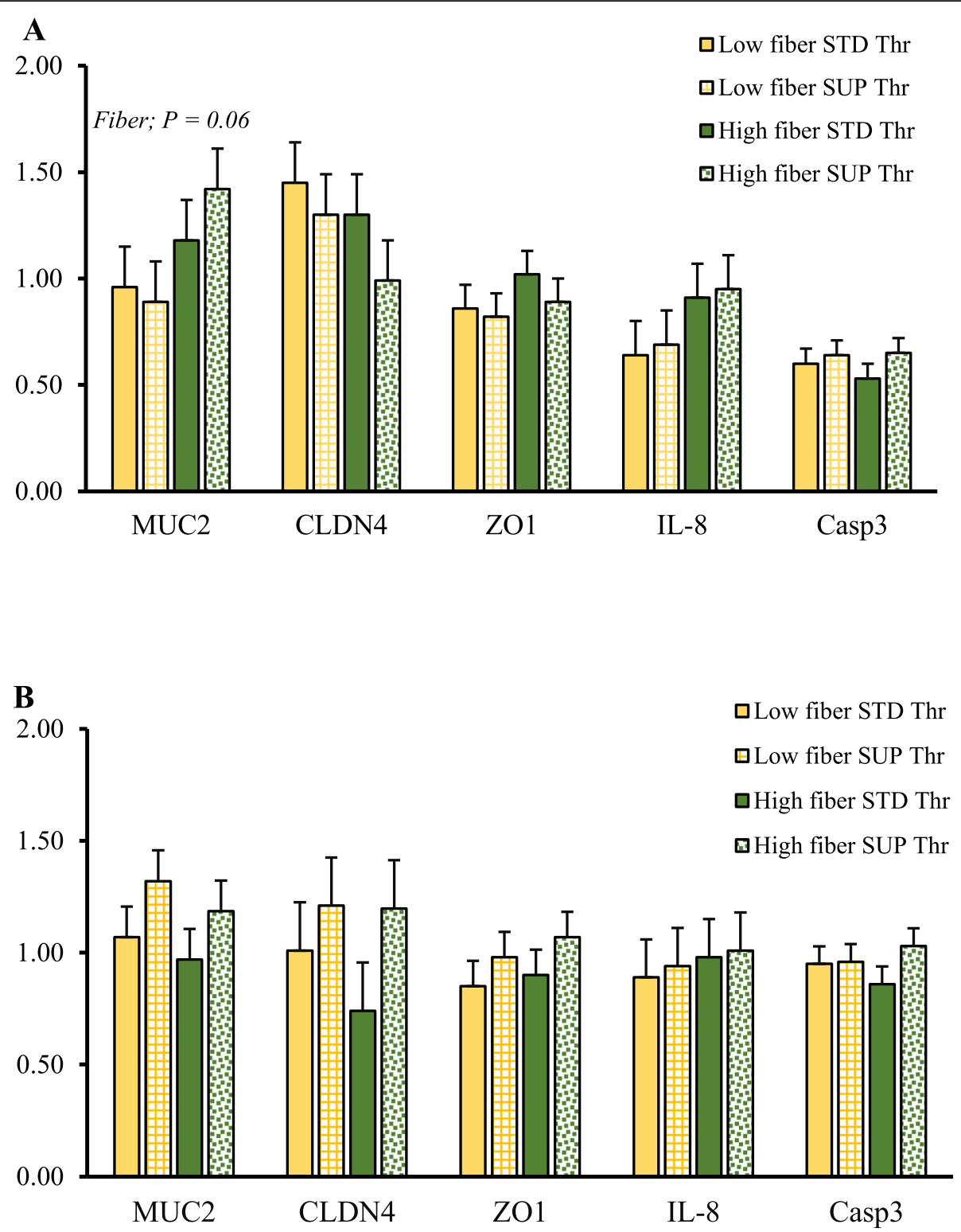

Fig. 5 lleal tissue (a) expression of marker genes for intestinal barrier function and colonic tissue (b) expression of marker genes for intestinal barrier function and. A total of 8 replicate pigs/treatment were used in the analysis. ZO1 = Zonular occludin-1; MUC2 = Mucin-2; CLDN-4 = Claudin-4; IL8 = Interleukin-8; Casp3 = Caspase-3

however, maximal mucin secretion in response to multiple challenges (e.g., disease challenge combined with high DF) may depend on dietary Thr supply. Finally, ileal morphology and goblet cell numbers were measured to ascertain the impact of dietary fiber and Thr on intestinal barrier function. No effects of fiber or Thr were observed on ileal mucosal morphology following the Salmonella Typhimurium challenge. A previous report by Hedemann et al. [56] suggested that feeding pigs high insoluble DF increased villi height and improved gut morphology, however, this effect may have been masked by the concurrent Salmonella Typhimurium challenge conditions reported here. Goblet cell numbers have been used as indicators of mucus secretion capacity in pigs $[27,50]$ where increases in goblet cell number, most importantly in the villus indicate an increased capacity [57]. The increase in goblet cell number with HF diets reported here agrees with reports from previous studies $[27,50]$. Different fiber sources (e.g. rye bran, oat bran) in the diet of golden hamsters were reported to increase goblet cell numbers in the intestine [58]. Further, Piel et al. [50] fed carboxymethylcellulose, a highly viscous and non-fermentable fiber to weanling pigs and reported a $30 \%$ increase in goblet cell number. The tight 
junction proteins (ZO-1, CLDN4) have been reported to play significant roles in regulating paracellular permeability and barrier function, as such changes in these proteins may indicate changes in intestinal permeability and barrier function [59-61]. However, no significant effect of fiber or Thr on relative expression of other target genes associated with barrier function was observed in the present study. This may be because the pigs used in this study were all challenged with Salmonella, as such that the response of the tight junctions to the treatments may have been masked by the effect of the ST challenge. The products of fermentation have been reported previously to improve intestinal health through mechanisms involving modification of microbial environment and composition [6, 41, 62]. Therefore, we measured VFA concentration in intestinal digesta, and the impact of these metabolites in relation to the expression of genes associated with intestinal health and barrier function. As expected, feeding high DF increased significantly the concentration of total VFAs in the cecum and colon digesta. Previous work in rats demonstrated that VFAs (acetate and butyrate) induce mucus secretion in rat colon $[63,64]$. Indeed, we observed a trend towards increased MUC2 expression in the ileum of pigs fed HF, which is consistent with the observed increase in goblet cell numbers. Although it has been suggested that mucin dynamics are affected by dietary Thr supply in chickens [65] we did not observe any significant effect of Thr levels on MUC2 gene expression or the expression of other target genes in the present study.

\section{Conclusion}

In conclusion, high DF appears to improve barrier function, as indicated by reduced L:M ratio, through an increase in mucin production capacity (i.e., goblet cell numbers, MUC2 gene expression) and synthesis (i.e., fecal mucin output). Furthermore, the lack of effect of dietary Thr on mucin production in Salmonella-challenged pigs fed low-fibre diets but not high-fibre fed pigs provides further evidence that mucin production in the gut is conserved and prioritized and may become limiting when multiple factors affecting mucin production are present. The current results provide information on the interactions of dietary composition and immune status that allow for development of feed programs that maintain performance while promoting gut health.

\section{Abbreviations}

AA: Amino acid; BW: Body weight; CFU: Colony forming unit; Casp3: Caspase3; CLDN4: Claudin-4; DF: Dietary fiber; GAPDH: Glyceraldehyde 3-phosphate dehydrogenase; HF: High fiber; IL8: Interleukin-8; ISS: Immune system stimulation; LPS: Lipopolysaccharide; LF: Low fiber; LM: Lactulose:mannitol; MUC2: Mucin-2; RPL19: Ribosomal protein-L19; SID: Standardized ileal digestible; STD: Standard; SUP: Supplemental; ST: Salmonella Typhimurium; Thr: Threonine; TDF: Total dietary fiber; VFA: Volatile fatty acid; ZO1: Zonula occludin-1

\section{Acknowledgements}

The authors would like to thank the staff and students at the Prairie Swine Centre, Inc., the Canadian Feed Research Centre, and the Animal Care Unit of the Western College of Veterinary Medicine for technical support. Special thanks to Cheryl Bock for assistance with lactulose/mannitol analysis.

\section{Authors' contributions}

DAC, AGVK, JKH and MOW designed the study, MOW, KH JECK conducted the study, MOW performed the statistical analysis of the data, MOW, AGVK and DAC wrote the manuscript. The manuscript was read and approved by all authors.

\section{Funding}

Funding for this project was provided by Alberta Agriculture and Forestry Strategic Research and Development Section, Evonik Nutrition \& Care GmbH, and Mitacs Accelerate.

\section{Availability of data and materials}

The datasets used and analysed during the current study are available from the corresponding author on reasonable request.

\section{Ethics approval and consent to participate}

The experimental protocols were approved by the University of Saskatchewan's Animal Research Ethics Board under protocols 20160107 and 20180123 and followed Canadian Council on Animal Care guidelines.

\section{Consent for publication}

Not applicable.

\section{Competing interests}

John K. Htoo is an employee of Evonik Nutrition \& Care GmbH. All other authors declare no conflicts of interest, financial or otherwise.

\section{Author details}

${ }^{1}$ Prairie Swine Centre, Inc., Saskatoon, SK S7H 5N9, Canada. ${ }^{2}$ Department of Animal and Poultry Science, University of Saskatchewan, Saskatoon, SK S7N 5A8, Canada. ${ }^{3}$ Evonik Nutrition \& Care GmbH, Hanau-Wolfgang, Germany.

Received: 30 October 2019 Accepted: 9 March 2020

Published online: 15 April 2020

\section{References}

1. Wells JM, Loonen LM, Karczewski JM. The role of innate signaling in the homeostasis of tolerance and immunity in the intestine. Int J Med Microbiol. 2010;300:41-8.

2. Wells JM, Rossi O, Meijerink M, van Baarlen P. Epithelial crosstalk at the microbiota-mucosal interface. Proc Natl Acad Sci. 2011;108:4607-14.

3. Farhadi A, Banan A, Fields J, Keshavarzian A. Intestinal barrier: an interface between health and disease. J Gastroen Hepatol. 2003;18:479-97.

4. Magalhaes JG, Tattoli I, Girardin SE. The intestinal epithelial barrier: how to distinguish between the microbial flora and pathogens. Semin Immunol. 2007:19:106-15

5. Che L, Chen H, Yu B, He J, Zheng P, Mao X, et al. Long-term intake of pea fiber affects colonic barrier function, bacterial and transcriptional profile in pig model. Nutr Cancer. 2014;66:388-99.

6. Chen H, Mao X, He J, Yu B, Huang Z, Yu J, et al. Dietary fiber affects intestinal mucosal barrier function and regulates intestinal bacteria in weaning piglets. Br J Nutr. 2013;110:1837-48.

7. McGuckin AM, Eri R, Simms LA, Florin TH, Radford-Smith G. Intestinal barrier dysfunction in inflammatory bowel diseases. Inflamm Bowel Dis. 2009;15: 100-13.

8. Ewaschuk JB, Murdoch GK, Johnson IR, Madsen KL, Field CJ. Glutamine supplementation improves intestinal barrier function in a weaned piglet model of Escherichia coli infection. Br J Nutr. 2011;106:870-7.

9. Zhu HL, Liu YL, Xie XL, Huang JJ, Hou YQ. Effect of I-arginine on intestinal mucosal immune barrier function in weaned pigs after Escherichia coli LPS challenge. Innate Immun. 2013;19:242-52.

10. Corfield AP, Myerscough N, Longman R, Sylvester P, Arul S, Pignatelli M. Mucins and mucosal protection in the gastrointestinal tract: new prospects for mucins in the pathology of gastrointestinal disease. Gut. 2000;47:589-94. 
11. Blank B, Schlecht E, Susenbeth A. Effect of dietary fiber on nitrogen retention and fiber associated threonine losses in growing pigs. Arch Anim Nutr. 2012;66:86-101

12. Molist F, Van Oostrum M, Pérez J, Mateos G, Nyachoti C, Van Der Aar P. Relevance of functional properties of dietary fiber in diets for weanling pigs. Anim Feed Sci Technol. 2014;189:1-10.

13. Saqui-Salces M, Huang Z, Ferrandis Vila M, Li J, Mielke JA, Urriola PE, et al. Modulation of intestinal cell differentiation in growing pigs is dependent on the fiber sources in the diet. J Anim Sci. 2017:95:1179-90.

14. Dharmani P, Srivastava V, Kissoon-Singh V, Chadee K. Role of intestinal mucins in innate host defense mechanisms against pathogens. J Innate Immun S Karger AG. 2009.

15. Faure M, Moennoz D, Montigon F, Fay LB, Breuille D, Finot PA, et al. Development of a rapid and convenient method to purify mucins and determine their in vivo synthesis rate in rats. Anal Biochem. 2002;307:244-51.

16. Libao-Mercado AJ, Zhu CL, Fuller MF, Rademacher M, Sève B, de Lange CFM. Effect of feeding fermentable fiber on synthesis of total and mucosal protein in the intestine of the growing pig. Livest Sci. 2007;109:125-8.

17. Munasinghe $\mathrm{LL}$, Robinson JL, Harding SV, Brunton JA, Bertolo RF. Protein synthesis in Mucin-producing tissues is conserved when dietary threonine is limiting in piglets. J Nutr. 2017;147:202-10.

18. Faure M, Moënnoz D, Montigon F, Mettraux C, Breuillé D, Ballèvre O. Dietary threonine restriction specifically reduces intestinal Mucin synthesis in rats. J Nutr. 2005;135:486-91.

19. Azzam MMM, Dong XY, Xie P, Zou XT. Influence of L-threonine supplementation on goblet cell numbers, histological structure and antioxidant enzyme activities of laying hens reared in a hot and humid climate. Br Poult Sci. 2012;53:640-5.

20. Azzam MMM, Zou XT, Dong XY, Xie P. Effect of supplemental L-threonine on mucin 2 gene expression and intestine mucosal immune and digestive enzymes activities of laying hens in environments with high temperature and humidity. Poult Sci. 2011:90:2251-6.

21. Wang X, Zeng X, Mao X, Wu G, Qiao S. Optimal dietary true ileal digestible threonine for supporting the mucosal barrier in small intestinal of weanling pigs. J Nutr. 2010;140:981-6.

22. Wellington MO, Htoo JK, Van Kessel AG, Columbus DA. Impact of dietary fiber and immune system stimulation on threonine requirement for protein deposition in growing pigs. J Anim Sci. 2018;96:5222-32.

23. Rakhshandeh A, de Lange CFM. Evaluation of chronic immune system stimulation models in growing pigs. Animal. 2012;6:305-10.

24. Wellington MO, Agyekum AK, Hamonic K, Htoo JK, Van Kessel AG, Columbus DA. Effect of supplemental threonine above requirement on growth performance of Salmonella typhimurium challenged pigs fed highfiber diets. J Anim Sci. 2019;97:3636-47.

25. Hurum D, Rohrer J. Determination of carbohydrates in urine by HPAE-PAD. Sunnyvale: Thermo Fisher Scientific; 2016.

26. Bovee-Oudenhoven I, Tremont D, Dekker R, Van der Meer R. Calcium in milk and fermentation by yoghurt bacteria increase the resistance of rats to Salmonella infection. Gut. 1996:38:59-65.

27. Swiech E, Tuśnio A, Barszcz M, Taciak M, Siwiak E. Goblet cells and mucus layer in the gut of young pigs: response to dietary contents of threonine and non-essential amino acids. J Anim Physiol Anim Nutr. 2019;103:894905.

28. Khorasani GR, Robinson PH, Kennelly JJ. Effects of canola meal treated with acetic acid on rumen degradation and intestinal digestibility in lactating dairy cows. J Dairy Sci. 1993;76:1607-16.

29. Lenahan M, Kelly S, Fanning S, Bolton DJ. The effect of bovine diet on Salmonella survival in synthetic abomasal fluid. J Appl Microbiol. 2010;109:2060-8.

30. Bach Knudsen KE, Hedemann MS, Lærke HN. The role of carbohydrates in intestinal health of pigs. Anim Feed Sci Technol. 2012;173:41-53.

31. Heinritz SN, Weiss E, Eklund M, Aumiller T, Louis S, Rings A, et al. Intestinal microbiota and microbial metabolites are changed in a pig model fed a high-fat/low-fiber or a low-fat/high-fiber diet. PLOS ONE. 2016;11(4): e0154329.

32. Shifflett DE, Clayburgh DR, Koutsouris A, Turner JR, Hecht GA. Enteropathogenic E. coli disrupts tight junction barrier function and structure in vivo. Lab Investig. 2005;85:1308-24.

33. Wu G. Functional amino acids in growth, reproduction, and health. Adv Nutr. 2010;1:31-7.

34. Mao X, Zeng X, Qiao S, Wu G, Li D. Specific roles of threonine in intestinal mucosal integrity and barrier function. Front Biosci. 2011;3:1192-200.
35. Kansagra K, Stoll B, Rognerud C, Niinikoski H, Ou CN, Harvey R, et al. Total parenteral nutrition adversely affects gut barrier function in neonatal piglets. Am J Physiol Gastrointest Liver Physiol. 2003;285:G1162-70.

36. Puiman PJ, Jensen M, Stoll B, Renes IB, de Bruijn AC, Dorst $K$, et al. Intestinal threonine utilization for protein and Mucin synthesis is decreased in formula-fed preterm pigs. J Nutr. 2011;141:1306-11.

37. Zhang Q, Chen X, Eicher SD, Ajuwon KM, Applegate TJ. Effect of threonine deficiency on intestinal integrity and immune response to feed withdrawal combined with coccidial vaccine challenge in broiler chicks. Br J Nutr. 2016; 116:2030-43.

38. Deng GY, Liu YW, He GZ, Jiang ZM. Effect of dietary fiber on intestinal barrier function of 5-Fu stressed rats. Res Exp Med. 1999;199:111-9.

39. Huygelen V, De Vos M, Willemen S, Tambuyzer B, Casteleyn C, Knapen D, et al. Increased intestinal barrier function in the small intestine of formulafed neonatal piglets. J Anim Sci. 2012:90:315-7.

40. Wijtten PJA, Verstijnen JJ, van Kempen TG, Perdok HB, Gort G, Verstegen MWA. Lactulose as a marker of intestinal barrier function in pigs after weaning. J Anim Sci. 2011;89:1347-57.

41. Li Q, Gabler NK, Loving CL, Gould SA, Patience JF. A dietary carbohydrase blend improved intestinal barrier function and growth rate in weaned pigs fed higher fiber diets. J Anim Sci. 2018:96:5233-43.

42. Wijtten PJ, van der Meulen J, Verstegen MWA. Intestinal barrier function and absorption in pigs after weaning: a review. Br J Nutr. 2011:105:967-81.

43. Courtois F, Seidman EG, Delvin E, Asselin C, Bernotti S, Ledoux M, et al. Membrane peroxidation by lipopolysaccharide and iron-ascorbate adversely affects Caco-2 cell function: beneficial role of butyric acid. Am J Clin Nutr. 2003;77:744-50

44. Sheth P, Samak G, Shull JA, Seth A, Rao R. Protein phosphatase 2A plays a role in hydrogen peroxide-induced disruption of tight junctions in Caco-2 cell monolayers. Biochem J. 2009:421:59-70.

45. Faure M, Choné F, Mettraux C, Godin J, Béchereau F, Vuichoud J, et al. Threonine utilization for synthesis of acute phase proteins, intestinal proteins, and Mucins is increased during Sepsis in rats. J Nutr. 2007;137:1802-7.

46. Faure M, Moennoz D, Montigon F, Mettraux C, Mercier S, Schiffrin E, et al. Mucin production and composition is altered in dextran sulfate sodiuminduced colitis in rats. Dig Dis Sci. 2003;48:1366-73.

47. Hoskins LC. Mucin degradation by enteric bacteria: ecological aspects and implications for bacterial attachment to gut mucosa. In: E.C. Boedeker (Editor). Attachment of organism to the gut mucosa. CRC press, Inc., Boca Raton, 1984; pp51-67.

48. Vercelloti JR, Salyers AA, Bullard WS, Wilkins TD. Breakdown of mucin and plant polysaccharide in the human colon. Can J Biochem. 1977;55:1190-6.

49. Moeser AJ, Van Kempen TA. Dietary fiber level and enzyme inclusion affect nutrient digestibility and excreta characteristics in grower pigs. J Sci Food Agric. 2002;82:1606-13.

50. Piel C, Montagne L, Sève B, Lallès JP. Increasing Digesta viscosity using Carboxymethylcellulose in weaned piglets stimulates lleal goblet cell numbers and maturation. J Nutr. 2005;135:86-91.

51. Brownlee IA, Havler ME, Dettmar PW, Allen A, Pearson JP. Colonic mucus: secretion and turnover in relation to dietary fiber intake. Proc Nutr Soc. 2003;62:245-9.

52. Lien KA, Sauer WC, He JM. Dietary influences on the secretion into and degradation of mucin in the digestive tract of monogastric animals and humans. J Anim Feed Sci. 2001;10:223-45.

53. Rakhshandeh A, Weber TE, Dekkers JCM, Tuggle CK, Kerr BJ, Gabler NK. Impact of systemic immune system stimulation on intestinal intergrity and function in pigs. FASEB J 2013; Vol 27 [1] supplement [abstr].

54. Lucke A, Böhm J, Zebeli Q, Metzler-Zebeli BU. Dietary deoxynivalenol and oral lipopolysaccharide challenge differently affect intestinal innate immune response and barrier function in broiler chickens. J Anim Sci. 2018;96:5134-43.

55. Rémond D, Buffière C, Godin JP, Mirand PP, Obled C, Papet I, et al. Intestinal inflammation increases gastrointestinal threonine uptake and Mucin synthesis in Enterally fed Minipigs. J Nutr. 2009:139:720-6.

56. Hedemann MS, Eskildsen M, Lærke HN, Pedersen C, Lindberg JE, Laurinen P, et al. Intestinal morphology and enzymatic activity in newly weaned pigs fed contrasting fiber concentrations and fiber properties. J Anim Sci. 2006; 84:1375-86.

57. McDole JR, Wheeler LW, McDonald KG, Wang B, Konjufca V, Knoop KA, et al. Goblet cells deliver luminal antigen to CD103 + dendritic cells in the small intestine. Nature. 2012;483:345-9. 
58. Lundin E, Zhang JX, Huang $\mathrm{CB}$, Reuterving $\mathrm{CO}$, Hallmans $\mathrm{G}$, Nygren $\mathrm{C}$, et al. Oat bran, Rye bran, and soybean hull increase goblet cell volume density in the small intestine of the golden hamster a histochemical and stereologic light-microscopic study. Scan J Gastroentero. 1993:28:15-22.

59. $\mathrm{Hu} \mathrm{CH}$, Xiao K, Luan ZS, Song J. Early weaning increases intestinal permeability, alters expression of cytokine and tight junction proteins, and activates mitogen-activated protein kinases in pigs. J Anim Sci. 2013;91: 1094-101.

60. Jiang J, Chen D, Yu B, He J, Yu J, Mao X, et al. Improvement of growth performance and parameters of intestinal function in liquid fed early weanling pigs. J Anim Sci. 2019:97:2725-38.

61. Richter JF, Pieper R, Zakrzewski SS, Günzel D, Schulzke JD, Van Kessel AG Diets high in fermentable protein and fiber alter tight junction protein composition with minor effects on barrier function in piglet colon. $\mathrm{Br} \mathrm{J}$ Nutr. 2014;111:1040-9.

62. Li Q, Burrough ER, Gabler NK, Loving CL, Sahin O, Gould SA, et al. A soluble and highly fermentable dietary fiber with carbohydrases improved gut barrier integrity markers and growth performance in F18 ETEC challenged pigs. J Anim Sci. 2019;97:2139-53.

63. Barcelo A, Claustre J, Moro F, Chayvialle JA, Cuber JC, Plaisancié P. Mucin secretion is modulated by luminal factors in the isolated vascularly perfused rat colon. Gut. 2000;46:218-24.

64. Chen HH, Chen YK, Chang HC, Lin SY. Immunomodulatory effects of xylooligosaccharides. Food Sci Technol Res. 2012;18:195-9.

65. Horn NL, Donkin SS, Applegate TJ, Adeola O. Intestinal mucin dynamics: response of broiler chicks and white Pekin ducklings to dietary threonine. Poult Sci. 2009;88:1906-14

Ready to submit your research? Choose BMC and benefit from:

- fast, convenient online submission

- thorough peer review by experienced researchers in your field

- rapid publication on acceptance

- support for research data, including large and complex data types

- gold Open Access which fosters wider collaboration and increased citations

- maximum visibility for your research: over $100 \mathrm{M}$ website views per year

At $\mathrm{BMC}$, research is always in progress.

Learn more biomedcentral.com/submissions 